\title{
Disruptive change and the reconfiguration of innovation ecosystems
}

\author{
Ozgur Dedehayir ${ }^{1}$, J. Roland Ortt ${ }^{2}$, Marko Seppänen ${ }^{3 *}$
}

\begin{abstract}
This conceptual paper extends the traditional view of disruptive change, which considers the effects of rivalry between an incumbent and new entrant firm, by examining the impact of disruption upon the 'innovation ecosystem' in its entirety - the group of organisations that collaborate in creating a holistic value proposition for the end-user. Following Adner's "ecosystem-as-structure" perspective, we develop propositions that anticipate structural differences between incumbent and disruptive innovation ecosystems, and then review these propositions in the context of three historical, disruptive innovation cases; Bakelite (a synthetic plastic), microwave oven, and photocopier. Through these cases, we illustrate that the manner of innovation ecosystem reconfiguration is likely to depend on the design attributes of the product, as well as the type of disruption experienced. We conclude by reflecting upon contemporary cases of disruption enabled through digital technologies, and proposing a framework that can guide future research.
\end{abstract}

Keywords: innovation ecosystem; ecosystem as structure; disruptive change; value blueprint; bakelite; microwave oven; photocopier.

Submitted: July $7^{\text {th }} 2017$ / Approved: September $11^{\text {th }} 2017$

\section{Introduction}

A long line of research has addressed the detrimental effects radical changes in the technological landscape can have upon firms (e.g. Tushman and Anderson, 1986; Bourreau et al., 2012; Carlsson, 2016). Following the 'creative destruction' argument of Schumpeter (1942), scholars have developed various frameworks to examine the evolution and revolution of technology-based industries. One of the most prominent frameworks has been introduced by Christensen (1997) to analyse the changes in the industry and the market, subsequent to the emergence of a so-called 'disruptive innovation'. Unable to find a foothold among mainstream customers due to its lack of performance, this new product initially serves a niche segment, beyond the strategic radar of incumbent firms competing for the mainstream market. Over time, however, the innovation attains sufficient performance levels to penetrate the larger customer segments and enter into rivalry with the incumbent technology, often displacing the latter due a different value proposition that is seen to be comparatively better. Unaware of the potential threat caused by the disruptive innovation, incumbent firms are compelled to exit the industry (e.g. Sandberg and Hansén, 2004; Currah, 2007; Da Silva et al., 2013).

Notwithstanding the value of this widely used theoretical model, there is growing interest in the way organisations create value collectively rather than as singular units (e.g. Adner, 2012; Adner, 2017). Hence, while the disruptive innovation framework is able to explain the consequences of radical innovations upon individual firms, there is need for greater understanding of the influence of disruption upon the larger, systemic context (see Adner and Kapoor, 2016a for a recent treatment of this issue). We subsequently aim to conceptualise the impact of disruption upon the 'innovation ecosystem', which connotes the heterogeneous set of organisations whose interactions deliver a holistic value proposition to the end-user (Moore, 1993; Garnsey and Leong, 2008; Brown, 2016). In line with Christensen's contributions, which have been to divulge the mechanisms of disruption and the derivation of implications for the incumbent (and disrupting) firm, our paper aims to illuminate how the innovation ecosystem changes subject to its disruption by a radically new technology, and arrive at implications for the firms that constitute the ecosystem. We feel this to be highly valuable for practitioners in particular, providing a more comprehensive analytical lens in their evaluation of the competitive environment.

Our conceptualisation essentially extends the traditional view of disruption as that resulting from the rivalry between incumbent and disrupting firms, to that ensuing between incumbent and disruptive innovation ecosystems. To understand the systemic effects of disruption, we employ the notion of the 'value blueprint' advocated by Adner (2012), which denotes the schema of actors and their connections necessary to deliver the innovation ecosystem's value proposition. Following Adner's (2017) suggestion that specific value propositions are delivered by unique ecosystem structures, we establish the premise that the value blueprint of the disruptive innovation ecosystem will be inherently different to that of the incumbent innovation ecosystem. Hence, from the perspective of any given actor in the ecosystem, the advent of disruption will essentially reconfigure the incumbent value blueprint as actors and their connections are necessarily adjusted. Some of these alterations may be detrimental while others reinforce the position of actors.

In our conceptual work we discuss the variables that may explain such reconfiguration, and derive propositions to explain how innovation ecosystem value blueprints are altered subsequent to disruptive technological change. We then review these propositions in light of three illustrative cases of disruptive innovation, namely, Bakelite (a fully synthetic plastic), the microwave oven, and the photocopier. In each of these cases, we use historical data to compare the value blueprints of the incumbent and disruptive innovation ecosystems. This

(1) Queensland University of Technology School of Management Brisbane, QLD, Australia

(2) Delft University of Technology Faculty Technology, Policy and Management The Netherlands

(3) Tampere University of Technology Department of Pori, Pori, Finland

${ }^{*}$ Corresponding author: marko.seppanen@tut.fi 
comparison essentially describes the reconfiguration of the incumbent ecosystem subject to disruption, as actors are added, subtracted, relocated, combined, or separated. In this manner, our work extends Adner's (2017) recent contribution that focuses more generically on the delivery of a new value proposition bought about by ecosystem structure reconfiguration. We conclude our paper by reviewing our conceptually derived propositions and illustrations, to propose a stylised framework, which can guide future research endeavours.

\section{Theoretical background}

\section{Innovation ecosystems}

The innovation ecosystem can be broadly defined as a set of organisations, which produces a holistic, integrated technological system (e.g. personal computers, smart watches, and online marketplaces) that creates value for customers (Teece, 2007; Agerfalk and Fitzgerald, 2008; Basole, 2009). This heterogeneous coalition may include suppliers, complementors, system integrators, and customers, together with distributors, advertisers, finance providers (e.g. venture capitalists, corporate investors, investment bankers, and angel investors), universities and research institutions, regulatory authorities and standard-setting bodies, and the judiciary (Whitley and Darking, 2006; Iyer and Davenport, 2008; Pierce, 2009;). Collectively, these actors "co-evolve capabilities around a new innovation" by working cooperatively as well as competitively in the creation of products and services (Moore, 1993). The mobile phone ecosystem (Basole, 2009), Amazon's web service ecosystem (Isckia, 2009), and Google's innovation ecosystem (Iyer and Davenport, 2008), are just some examples of ecosystems that centre on respective innovations.

Commensurate with its biological metaphor origins, some scholars have emphasised the indispensability of the 'keystone' (Iansiti and Levien, 2004) or 'platform leader' (Cusumano and Gawer, 2002) that lies at the core of the innovation ecosystem. The keystone's role is to regulate the overall function of the ecosystem and as a consequence its actions influence the success of all other members. Firms such as Microsoft, Apple, and Mozilla have been crucial platform leaders, ensuring the continued development of their respective ecosystems
(Cusumano and Gawer, 2002; Tiwana et al., 2010). The keystone is supported by a further category of actors referred to as 'niche players', which undertake specialised functions. Niche players can also be referred to as 'complementors' given that their specialised contribution is complementary to the core function of the platform leader, and which helps expand the realms of the latter's products and services. In this manner, by focusing on the "communities of associated actors defined by their networks and platforms affiliations" (Adner, 2017, p.40), scholars assume what Adner (2017) refers to as an "ecosystemas-affiliation" perspective of innovation ecosystems.

In this paper, we predominantly employ the alternative, "ecosystemas-structure" perspective of the innovation ecosystem advanced by Adner (2017), underscoring the "configurations of activity defined by a value proposition" (Adner, 2017, p.40). Lying at the core of this view is the ecosystem's value proposition, which defines the benefits that the end-user will accrue from acquiring the final product. In turn, the value proposition defines the set of actors whose interactions and alignment structures (i.e. defined positions and activity flows) will ultimately bring the proposition to fruition (Adner, 2017). It therefore follows that even when the same set of actors are involved, reconfiguring the ecosystem's structural alignment will deliver a different value propositions, and therefore denote two different ecosystems.

To assist organisations in recognising the ecosystem surrounding them and analysing the process of value creation, Adner (2012) additionally proposes the notion of a 'value blueprint'. Specifically, the value blueprint is a schema of the actors and the connections between these actors that constitute the innovation ecosystem. Within in this schema, we can identify three generic categories of actors with respect to a focal firm: (i) suppliers (i.e. upstream actors), whose products are integrated into the focal firm's own offering; (ii) complementors (i.e. actors off the direct-path of value creation), whose products complement that of the focal firm; and (iii) customers, (i.e. the downstream actors, including intermediaries) who integrate the offering of the focal firm and complementors to acquire enhanced value. The basic, generic unit of the innovation ecosystem value blueprint is shown in Figure 1.

Figure 1. Generic value blueprint (adapted from Adner 2012, p. 87).

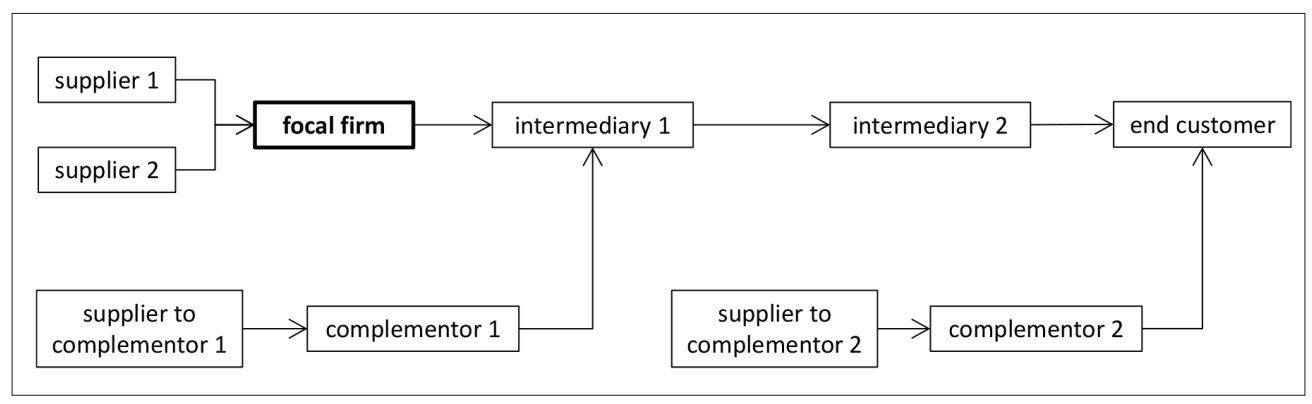

While the traditionally used value chain (e.g. Porter, 1985) and supply chain (e.g. Simchi-Levi, 2005) depictions "tend to focus on the linear sequence of handoffs from suppliers to producers to distributors to end customers, the value blueprint is explicit about the specific location and links of complementors that lie off the direct path to market but are nonetheless critical for success" (Adner 2012, p. 84). A significant benefit of the value blueprint framework is the identification of the location risks, or potential bottlenecks, which can curb the 
development of the ecosystem as a whole. The removal of these blockages emerges as most pertinent in promoting ecosystem evolution (Adner and Kapoor, 2010; Mäkinen and Dedehayir, 2013).

The interdependence of ecosystem members and the products they contribute is therefore a prime driver of ecosystem development. Under these circumstances, the presence of a clear platform architecture promotes co-evolutionary processes in ecosystems where complementors and component makers produce distinct technological sub-systems ( $\mathrm{Li}, 2009)$. The platform leader plays a central role in this change dynamic, and has strong motivation to design the ecosystem's architecture, which must be done by forecasting future changes given the often irreversible nature of platform architecture (Tiwana et al., 2010). Such platform design can be aided by 'decomposition', which connotes the breaking down of the architecture in a hierarchical manner into its constituent sub-systems. The benefit of decomposition is the reduction of interdependence between the evolutionary processes of components that make up the ecosystem, which in turn accelerates the evolution of sub-systems while concurrently reducing ecosystem complexity (for a recent discussion of interdependence and timing issues in ecosystems see Adner and Kapoor, 2016b). An element that is central to the design of architectures is therefore the degree of independence between subsystems, referred to as 'modularity' (e.g. Baldwin and Clark, 2003).

Platform architectures can vary from highly modular to highly integrated in their designs. Architectures that classify in the latter end of the spectrum face the challenge of cascading effects as changes in one sub-system are reverberated throughout the ecosystem. Platform leaders that design platform architectures can increase modularity by decoupling sub-systems and standardising the interfaces between them such that they are predefined and stable. Following the arguments of modular systems theory (e.g. Schilling, 2000), we may infer that innovation ecosystems displaying a high degree of modularisation are likely to experience a higher rate of evolution, because modules can evolve independently of others, with less need for coordination and understanding of the internal functioning of other modules. At the same time, the costs incurred in coordination and management of dependencies with other modules and the platform is reduced in modular ecosystems, which once again benefits the evolution of modules and the ecosystem as a whole (Tiwana et al., 2010).

\section{Disruption of innovation ecosystems}

Disruptive innovations cause paradigm shifts and establish new trajectories of technological improvement (e.g. Bower and Christensen, 1995; Christensen, 1997). Because a disruptive innovation initially lacks the performance levels necessary to compete with the incumbent technology along value dimensions that are most pertinent to mainstream customers, it is nurtured in a separate (e.g. nascent or emergent) market that appreciates a different value proposition. However, through a series of improvements, the disruptive innovation attains the necessary performance levels valued by the mainstream market, and offers a competitive solution to that of the incumbent technology. Moreover, the disruptive innovation is highly competitive among mainstream customers because it additionally carries the value proposition that has been central in its initial nurturing market.
Disruption triggers a period of competition among the firms that provide the incumbent and disruptive innovations, potentially resulting in the incumbent firms' replacement by the firms that introduce the new innovation. Christensen's description of disruptive change subsequently has profound implications for the incumbent firm, however, the impact of disruption upon the actors that are directly (or indirectly) connected with the incumbent firm - i.e. the incumbent innovation ecosystem - is not considered in this description. To understand the impact of disruption on the incumbent innovation ecosystem, we begin by considering its value blueprint depicted in Figure 1. Following the "ecosystem-as-structure" perspective (Adner, 2017), this schema presents the constellation of organisations that collaborate in delivering the incumbent value proposition to the end-user. However, the introduction of a disruptive innovation brings with it a radical shift in the attributes appreciated by customers in this market, commensurate with Christensen's (1997) framework. This new value proposition will be delivered by an innovation ecosystem that is different from the incumbent with respect to its structure, in other words, the position of actors and the flow of activities between them, no matter whether the same actors are present or not (Adner, 2017).

The emergence of a disruptive innovation thus brings two innovation ecosystems into rivalry, and the succession of the disruptive ecosystem over the incumbent establishes a new structure of actors and connections - essentially reconfiguring the incumbent ecosystem's value blueprint. This reconfiguration can be brought about by: (i) 'relocation' of actors and the tasks allocated to them; (ii) 'separation' of a single task into separate tasks to be undertaken by different actors; (iii) 'combination' of separate tasks to be undertaken by a single actor; (iv) 'addition' of new actors to undertake tasks that are currently absent but would benefit the ecosystem; and (v) 'subtraction' of existing actors and their tasks to benefit the ecosystem (Adner, 2012). Through these reconfiguration mechanisms, we may, for instance, anticipate the replacement (i.e. subtraction followed by addition) of the incumbent focal firm in Figure 1 by the focal firm of the disrupting ecosystem, when the product of the latter substitutes for that of the former. This process aligns with Christensen's model, which considers the rivalry between the incumbent firm and new entrant. However, for the other actors that constitute the incumbent ecosystem (i.e. lying upstream, downstream, and in complementary positions in the ecosystem's value blueprint), we suggest that the manifestation of relocation, separation, combination, addition, or subtraction processes will be governed by two key factors: (i) the nature of the disruptive innovation; and (ii) the degree of modularity of the incumbent product or service.

The traditional mode of disruptive change described by Christensen (1997), referred to as low-end disruption, is characterised by the lower unit price and design simplicity of the disruptive innovation in comparison to the incumbent. Through these product traits the disruptive innovation attracts the price-sensitive segments of the mainstream market at first, and then gradually captures the less price-sensitive segments due to its comparatively better value proposition. We consider two pathways along which the innovation ecosystem' structure can be reconfigures to deliver this new value proposition, which emphasises the reduced price and complexity of the product or service. 
First, the ecosystem structure can attain efficiency and economies of scope by dispensing with redundant processes while combining other processes (e.g. through insourcing, and merger and acquisition activities). The value blueprint of the disruptive innovation ecosystem will therefore be simpler, pronounced by a lower number of actors and connections in comparison to that of the incumbent ecosystem value blueprint. Combination and subtraction are likely to be the dominant modes of ecosystem value blueprint reconfiguration when following this pathway. Second, and somewhat in contrast to the first pathway, the price and design benefits can materialise from the introduction of a platform architecture and increased modularisation (Gawer, 2014; Gawer and Cusumano, 2014). Following this pathway, unit price reduction and product design simplicity results from the division and distribution of multiple tasks previously undertaken by a single actor to a number of specialised actors (e.g. through outsourcing activities). Separation and addition are likely to be the dominant modes of ecosystem value blueprint reconfiguration when this second pathway is followed.

In light of the two reconfiguration pathways we have considered, the natural line of inquiry pertains to the conditions that promote one pathway in preference to the other. We argue that an incumbent innovation ecosystem, which delivers a product or service that is modular rather than integrated in its design, will be more susceptible to disruption by an innovation that is platform-based and boasts an even higher degree of modularity - thus promoting the second pathway. In this instance, we suggest that the modular design of the incumbent product or service essentially sets the precedent for the disruptive innovation, which can readily accentuate and refine this modular concept. The reduced unit price and complexity of the disruptive innovation can therefore be achieved through an ecosystem structure that centres about a distinct, core platform, for which a multitude of modules can be developed by numerous actors who specialise in the provision of complementary assets (Teece, 1986; Sawhney, 1998; Gawer, 2014). By contrast, we argue that the disruption of an incumbent product or service, which is not modular in its design, cannot be as readily attained through such platform and modularisation strategy, given the greater difficulty in its decomposition. Other strategies are therefore likely to be sought to lower price and reduce design complexity - thus promoting the first pathway. These arguments lead us to make the following propositions with respect to the reconfiguration of the innovation ecosystem value blueprint.

Proposition 1: The reconfiguration of the incumbent innovation ecosystem value blueprint, subsequent to low-end disruption, is likely to be characterised by separation and addition when its product or service is modular.

Proposition 2: The reconfiguration of the incumbent innovation ecosystem value blueprint, subsequent to low-end disruption, is likely to be characterised by combination and subtraction when its product or service is not modular.

These propositions extend the effects of low-end disruption to the innovation ecosystem in its entirety. In Proposition 1, we suggest that new actors are likely to enter the ecosystem, especially as complementors to the platform leader, when the incumbent product or service is modular. By contrast, Proposition 2 offers caution to incumbent suppliers, intermediaries, and complementors, which face the possibility of exiting the ecosystem with the advent of disruption, when the incumbent product or service is not modular.

Further to the traditional, low-end disruption discussed so far, Christensen and Raynor (2003) underline an additional mechanism through which an incumbent firm faces disruptive competition. This second type of disruption - referred to as new market disruption - does not bring the incumbent and the new entrant into direct competition. Rather, in the words of Christensen and Raynor, "new market disruptions compete against non-consumption" and not the incumbent. In this manner, the period following the inception of the new market innovation is marked by the creation of consumption. As the innovation's performance improves, customers from the traditional market gradually migrate to the new context that had been marked by non-consumption at its outset. The response of incumbent firms to the creation of a new market is one of ignorance, eventually leading to their downfall as the traditional market is siphoned away. This mechanism is different to that of low-end disruption, which is pronounced by the disruptive innovation's invasion of the mainstream market with a low-cost business model, forcing incumbents to flee to higher segments of the market. Christensen and Raynor (2003) add that many disruptive changes are hybrids of low-end and new market disruption, whereby, having created a new market, the disruptive innovation begins to attract and pull the lower echelons of the mainstream market.

Unlike low-end disruptions, new market disruptions do not necessarily compete on lower price. As a consequence, the incumbent innovation ecosystem faces competition from a new market or hybrid disruptive innovation, which offers a better value proposition in the eyes of the customer, despite its higher unit price. Such a value proposition may, for instance, provide additional product or service features, or enhance the functionality of existing ones. Under these conditions, we argue that the comparatively better value offering is likely to result from the addition of complementary assets to the disruptive innovation ecosystem structure. We subsequently offer the following proposition with respect to the reconfiguration of the innovation ecosystem value blueprint.

Proposition 3: The reconfiguration of the incumbent innovation ecosystem value blueprint, subsequent to new market disruption created by an innovation of higher price vis-à-vis the incumbent, is likely to be characterised by addition.

This proposition suggests that new market disruptions can provide opportunities for new businesses to enter the innovation ecosystem, following a similar logic to that of Proposition 2. Especially when the product or service is modular in its design, we posit that these new entrants are likely to assume complementary positons that enhance the value offering of the platform leader. 


\section{Illustrations}

To examine our propositions, we selected three illustrative, historical cases to provide contrasting results. These cases were drawn from different contexts, and allowed us to access rich information to study the value blueprint reconfigurations of respective innovation ecosystems. We firstly focus on Bakelite, and its use as an electric insulator that rendered it a disruptive innovation, and which changed the market hitherto dominated by Shellac, a natural material with isolating properties. Secondly, we look at the microwave oven, a disruptive innovation that changed customer demand in the cooking market by enabling fast cooking and allowing preparation of ready deep-frozen meals. And we thirdly examine the Canon photocopier, which emerged as a disruptive innovation through its much simpler design with respect to the incumbent Xerox copier.

For each illustrative case a systematic literature search was performed using keywords representing the names of the innovations (i.e. Bakelite, microwave oven, and copier) and additional keywords such as 'history' and 'diffusion' to filter the acquired literature. In turn, the cases were studied systematically to address the following aspects for each instance of disruption:

i. description of the incumbent technology, and its ecosystem value blueprint prior to being challenged by the disruptive innovation

ii. historical account of the disruptive innovation's development and the creation of the disruptive innovation ecosystem

iii. review of the innovation ecosystem value blueprint reconfiguration

\section{Bakelite}

Bakelite is one of the first fully synthetic plastics, and like other materials, has been used in many applications. We will focus on a particular episode in the history of Bakelite, namely, its use as an insulator of electric wires, which illustrates the disruptive nature of the innovation as it entered competition against Shellac, a natural material traditionally used for this same purpose.

\section{Description of the incumbent technology (Shellac)}

Shellac is a natural material produced by an insect. The lac that is produced by the insect is left on branches of trees that host the insect. At first the lac was seen as a dye, but when aniline dyes were discovered, the lac was more and more applied as a kind of varnish from the late 19th century onwards (Hicks, 1961), used for many purposes (Parry, 1935; Hicks, 1961). Some of the applications of Shellac include its use as an essential component in phonograph records, as an electrical insulating material, and as an ingredient in the making of hats and grinding wheels (Hicks, 1961). For the purposes of this study, however, we focus our attention on the use of Shellac as an electric insulating material.
In the 19th century electricity and electronics became increasingly important in our society. In the second half of the 19th century telegraphy and later telephony required insulation of electric wires (Huurdeman, 2003). In the late 19th century a greater number of cities in the US and Europe were equipped with electricity networks and many rural areas were equipped with local electricity networks (Righter, 1996). All of these activities required considerable amounts of insulating material. Shellac had unique properties in this respect.

The production of Shellac as a natural material was mainly based in specific regions in India. The process of cultivating the material, taking the lac from the branches, preparing and refining the material, gathering and transporting the lac, trading it to Europe or the US entailed a complete and fine-branched network (Parry, 1935). After the transport from Calcutta, India, (the regional trading and transport centre near production) to London, UK, (the regional centre where Shellac was sold to users in Europe) the material could be further refined and reworked into phonograph records, insulation for electric wires, and so on.

The increasing demand and the limited supply of Shellac drove up the price of the material, however, which was further exacerbated during the Second World War. Shellac had many military applications and because of its strategic importance the supply of the material came under Government control. When these controls were lifted after the war, the prices rose to a prohibitive level for uses such as record production, thereby stimulating the search for synthetic resins (Hicks, 1961).

\section{Development of the disruptive innovation (Bakelite)}

In the second half of the 19th century many scientists and practitioners tried to create plastic-like materials. At first these materials were based on cellulose that was treated with chemicals. From these efforts materials such as Rayon, Celluloid and other semi-synthetic materials were created (Kauffman, 1993; Townsend, 1993). Later on, precursors of the fully synthetic plastics were created such as Parkesine but these materials were unsuccessful in the market. Bakelite was one of the first successful synthetic materials.

Baekeland, the chemist who developed Bakelite, recognised that the demand for Shellac would outpace supply because of the increased importance of electricity in Western Societies and the limitation in supply. He started to work in a barn behind his house in 1904 and was able to create the first true plastic in 1907. Small-scale production of the plastic began from the same location. Later on in 1911, when demand grew, large-scale production started in a factory.

'Baekeland's first patent in the field had been granted in 1906; in all, he took out more than 400 patents related to the manufacture and applications of Bakelite. He started semi-commercial production in his laboratory and, in 1910, when daily output had reached 180 litres, (most of it for electrical insulators), he formed a U.S. company to manufacture and market his new industrial material. By 1930, the Bakelite Corporation occupied a 128-acre plant at Bound Brook, New Jersey.'

(http://www.acs.org/content/acs/en/education/whatischemistry/ landmarks/bakelite.html\#invention-of-bakelite) 
The disruptive nature of Bakelite was born from its good performance, but most importantly, from its potential to be produced in an industrial process. This production characteristic had two positive effects. Firstly, the potential for higher supply quantity lowered the price of the new technology with respect to that of the incumbent Shellac. Secondly, the capacity to control the production process meant that higher consistency in quality could be obtained. This value attribute could hardly be provided by the natural material Shellac, the quality of which depended heavily on its geographic origin of the raw material and the conditions of the particular season in which this material had been cultivated. The quantity and quality performance attributes displayed by Bakelite were initially valued by the emerging electrical and automobile industries, which required extraordinarily high resistance to electricity, as well as to heat and chemical action.

\section{Reconfiguration of the innovation ecosystem value blueprint}

From the description above, we are able to discern some of the key actors that constituted the incumbent ecosystem centring on Shellac technology. Positioning the value blueprint about the focal firm as the actor that produces insulation for electric wires using Shellac, the direct customers appear to be the firms that provide electricity networks (electricity providers). Upstream from the focal firm, there is a complex network of suppliers responsible for the cultivation, collection, and refinement of the material (e.g. in India), as well as actors engaged in intercontinental transportation of this material and local distributors of this material that may supply directly to the focal firm.

We observe a rather substantial reconfiguration of the incumbent value blueprint when we contrast it to that of the Bakelite ecosystem at the time of disruption. The value blueprint created about the disruptive Bakelite innovation began with Baekeland's invention, and gradually increased in the number of actors as large-scale production was attained. The fully synthetic nature of Bakelite, in stark contrast to the natural material that forms Shellac, created an ecosystem that was largely locally based. Together with this, the modern industrial system necessary to produce Bakelite rendered the actors needed to cultivate, collect, and refine raw materials redundant, as well as the actors associated with long distance transportation. The disruption of the Shellac innovation ecosystem by Bakelite subsequently had severe effects on the survival of actors upstream from the focal firm.

\section{The microwave oven}

The value proposition of the microwave oven was a new, very fast way of cooking. The first microwave ovens were applied in market niches where speed was considered as an important value attribute and space was limited, such as in restaurants, trains, and ships. These performance attributes, which were central to the development of this innovation eventually changed the traditional market for cooking in households.

\section{Description of the incumbent technology (traditional ovens)}

Prior to the advent of the microwave oven, the traditional cooking technologies included cooking stoves and ovens fuelled by gas and electricity, as well as barbeques or grills that burned coal and wood. We consider these as the incumbent technologies that were (partially) disrupted by the microwave oven innovation. These incumbent appliances (still continuing their market presence, albeit for slower, more intricate cooking procedures) work on several principles. The dominant principle is that water is heated and food is boiled, but other principles such as steaming, grilling or roasting are also traditionally used. These principles of cooking nevertheless require a lot of energy and time.

\section{Development of the disruptive innovation (microwave oven)}

The innovation of the microwave oven was made possible with the discovery of a crucial component in the early 20th century, namely, the microwave tube. Remaining merely as an invention in its early days, the worldwide economic depression of the late 1920s and early 1930s forced power tube manufacturers to explore new applications for the microwave tubes.

'There is some reference in the "early history of industrial electronics," (..) to the fact that the principal high-power tube manufacturers were forced by the depression years to find new tube applications and some of these were in heating-mostly in induction heating and early diathermy work.'

(Osepchuk, 1984, p.1202)

Several market niches that could transform the invention into a commercialised innovation were explored by the firm Raytheon. Military application was one of the most promising, whereby microwave tubes were applied in radars during the Second World War. However, the end of World War II would vanish Raytheon's lucrative military contracts. The accompanying revenue drop required Raytheon to explore new civilian applications (Hammack, 2005). Among other possible civilian applications, employing microwave principals for cooking was a radically new idea.

'The commonly used radio wave frequency is roughly 2,500 megahertz (2.5 gigahertz). Radio waves in this frequency range have an interesting property: they are absorbed by water, fats and sugars. When they are absorbed they are converted directly into atomic motion -- heat. Microwaves in this frequency range have another interesting property: they are not absorbed by most plastics, glass or ceramics. Metal reflects microwaves, which is why metal pans do not work well in a microwave oven. In microwave cooking, the radio waves penetrate the food and excite water and fat molecules pretty much evenly throughout the food. There is no "heat having to migrate toward the interior by conduction". There is heat everywhere all at once because the molecules are all excited together.' 
Having found a civilian application for the microwave tube, namely cooking, the microwave oven entered market niches where its functional attributes (speed of cooking and smaller space requirements) were appreciated. In time, the microwave oven was able to enter the mainstream market of household cooking, and upon entering changed the value perception of this market. With its capacity to cook as well as the incumbent technologies (ovens and stoves), it introduced the added benefits of convenience and speed that enabled it to gain a stronghold in household kitchens. Moreover, convenience was not only provided by the speed of cooking per se but also by the opportunity to quickly prepare deep-frozen meals. Nevertheless, the first microwave ovens were rather expensive and therefore attracted the less price-sensitive segments of the mainstream market initially. Over time, however, with lowering of prices, the innovation was able to penetrate into the more price-sensitive segments as well.

\section{Reconfiguration of the innovation ecosystem value blueprint}

The comparison of the incumbent and disruptive value blueprints reveals some important differences. The value blueprint of the long established, incumbent technologies are pronounced by the presence of complementors that provide energy sources, such as coal, gas, or electricity, as well as cookware (e.g. oven proof casserole dishes, pots, and pans). In this manner, the end-user integrates the hardware (the traditional oven and stove) with the energy components and cookware to enable cooking. This complementarity extends the value blueprint off the direct path of value creation with the presence of a host of actors that compete in their respective industries.

The entrance of the microwave oven into the household kitchen market does not fully align with the traditional view of disruptive change, however. The innovation offers a different set of value attributes with respect to the incumbent, although it has, for the most part, assumed a complementary role rather than one of complete substitution. Hence, many kitchens have been equipped with both the traditional oven as well as the microwave oven. Nevertheless, the disruptive nature of the microwave oven is manifested in its attraction of many end-users away from the incumbent technologies over time. This process has been enabled by the enhancement of holistic value that the end-user has been able to acquire from the innovation. Most notably, the new principle of cooking endowed by the microwave oven stimulated the innovation of new ways of food preparation and new ways of food packaging. Ready and pre-packaged meals can be frozen and subsequently heated quickly if the proper packaging materials are applied. This emergent chain of food production and packaging (addition of new actors into the ecosystem) aligns with the value attributes of speed and convenience consumers associate with the microwave oven instead of remarkably improved energy efficiency that was considered as key advantage in the original patent application (Osepchuk, 1984). At the same time, some of the actors that have provided cookware for the traditional oven have been able to contribute also to the microwave oven value blueprint by developing microwave safe dishes.

\section{The photocopier}

The Canon photocopier disrupted the mainstream market dominated by the incumbent Xerox copier, assuming a highly competitive position through the simplicity of its design. Despite displaying lower performance than the incumbent at the outset, its lower price allowed it to penetrate particular market segments, namely, the SMEs (small and medium-sized enterprises).

\section{Description of the incumbent technology (Xerox copier)}

The early photocopier industry was dominated by the prevailing business model of wet photography and dry thermal processing, akin to the 'razor' and 'razor-blade' model. A typical machine would cost around $\$ 300$ (Chesbrough, 2003). Xerox, the pioneer of photocopier machines based on the electrostatic charge process, estimated that the manufacturing cost of their machines would be about $\$ 2000$, while the variable cost of supplies would remain roughly the same (Chesbrough, 2003). This created a major challenge for the commercialisation of the technology: the 'razor' was much more expensive while the 'blade' was no cheaper. The company used a different business model to overcome the high equipment cost, offering customers the option to lease. Customers needed to pay a nominal $\$ 95$ per month to lease a machine, and paid a nominal amount per copy. With this new business model Xerox had essentially taken a bet as it assumed that the number of copies would increase considerably, and only then was it possible to make a profit.

Commensurate with their new approach, Xerox introduced the model 914 to the market in 1959. The 914's business model generated more revenue when more copies were made, which established the logic for Xerox's copier business (Chesbrough and Rosenbloom, 2003). The company focused on high-speed, high-volume machines, which inevitably established the paradigm for technological development within the industry. As it was complex to repair these machines, Xerox decided to use its own sales force to lease as well as to repair the machines, simultaneously dispensing with the requirement of partnerships. Xerox manufactured its products, made its own paper to provide optimal feeding and even provided finance for customers.

\section{Development of the disruptive innovation (Canon copier)}

Meanwhile Xerox's monopoly ended abruptly in the late 1960s, when the Federal Trade Commission forced the company to license its patents to competitors. IBM and Kodak entered this newly created industry. Both these companies focused on high-speed, highvolume copiers (i.e. following the same technological trajectory set by Xerox), using a business model similar to that of Xerox. Fundamentally, their strategy was to capture a share of Xerox's market by offering better products or better services at lower prices. Neither of these companies, however, managed to take a decent share in the copier business. 
In the meantime, Canon found a way to circumvent Xerox's patents by designing a distinctive strategic position to enter the photocopier industry. In contrast to Xerox, Canon focused on SMEs as its target market and decided to sell its machines through a dealer network rather than leasing them. While Xerox emphasised the speed of its machines, Canon elected to concentrate on affordability and ease of use and repair as its differentiating features. The product design was simplified so customers could replace spare parts and could perform simple repairs. In this way, a dealer network was able to handle the customer contacts.

Canon was also able to correct Xerox's failed attempt at the 'razor' and 'razor-blade' model by asking a modest 'box cost' for the copier and earning higher margins on cartridges. Moreover, Canon continued to depart from Xerox's business model by outsourcing the distribution, service, support, and financing functions (Chesbrough, 2003). Xerox attempted to enter this mass market in response, but learned that the business model was entirely different. In 2001, the company was compelled to abandon its presence in the low-end market, and decided to stick to its original high-end market segment.

The Canon copier subsequently disrupted the market as a cheap and simple alternative to the incumbent copier made by Xerox. It altered the value perception of the mainstream market, emphasising the low price for the copying machine and the convenience of simple procedures required to replace parts of the machine when repairs were required.

\section{Reconfiguration of the innovation ecosystem value blueprint}

This case study illustrates a radical shift in the value blueprint of the incumbent innovation ecosystem as it is supplanted by the disruptive ecosystem. The former has been shaped by Xerox's business model which has been pronounced by a high level of internalisation of functions. In addition to producing its own machines, the company had decided to horizontally integrate certain complementary products and services, including paper, leasing, repair, and financing. The resulting incumbent value blueprint had relatively few complementors. In stark contrast, Canon's disruptive value blueprint was marked by a much larger network of collaborators. By outsourcing key functions that Xerox had internalised, Canon was able to reduce the price tag of its copiers. Canon had essentially provided a totally new platform with clear interfacing that allowed modules (products and services) to be readily connected to Canon's core product. This strategy added new actors to the value blueprint both as intermediaries and complementors, dealing with functions such as distribution, service, support, and financing.

\section{Discussion and conclusions}

The objective of our paper has been to explain how innovation ecosystems change under the influence of disruptive innovations, and consequently, to identify the variables that may explain the reconfiguration of the ecosystem's value blueprint. In essence, the disruptive process brings two innovation ecosystems into rivalry, whereby the ecosystems provide different value propositions, and therefore have different value blueprints (Adner, 2017). The reconfiguration of the incumbent ecosystem value blueprint through addition, subtraction, relocation, separation, and combination mechanisms, are the results of this rivalry. The Bakelite case, for example, underlined the subtraction of multiple actors in the supply side of the incumbent value blueprint as new actors specialised in industrial production entered the fray. In the microwave oven case we observed the addition of new complementors, and our study of the photocopier case revealed significant reconfiguration of the incumbent value blueprint marked by the separation of tasks that were owned by new actors. The various modes of value blueprint reconfiguration we have divulged through these illustrative cases are presented in Table 1.

Table 1. Innovation ecosystem value blueprint reconfigurations and characteristics of disruption.

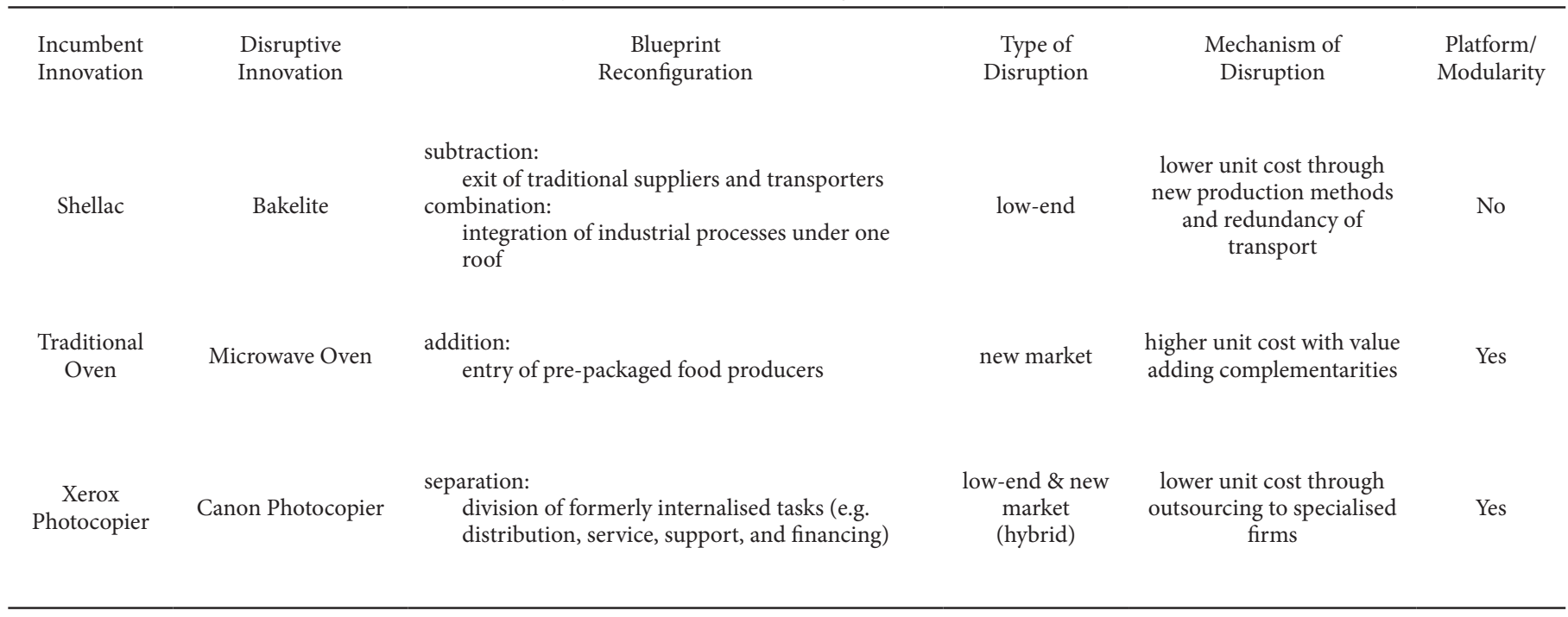


The illustrative cases demonstrated that the type of disruptive change is a primary determinant of the mode of value blueprint reconfiguration. Two of the cases considered in our paper - Bakelite and the Canon photocopier - underline low-end disruption. In both of these cases, the disruptive innovation offered a lower price than the incumbent innovation, namely, Shellac and the Xerox copier, respectively. The disruptive innovations were able to outcompete their incumbent rivals because of their superior value propositions, which not only delivered relatively lower price tags, but also additional benefits, including quantity abundance as compared to the limited availability of Shellac in the case of Bakelite, and flexibility and ease of usage as compared to the strict operation procedures of the Xerox copier in the case of the Canon photocopier.

When we compare the value blueprint reconfigurations, however, we observe different outcomes. In the Bakelite case, the lower price of the innovation appears to have been acquired through two processes: (i) a radical change in production methods (i.e. a synthetic, industrial process as opposed to the quasi-agricultural process for Shellac); and (ii) the redundancy of transportation links. The impact on the ecosystem value blueprint has been that of combination - bringing together different processes under an industrial roof - and subtraction - elimination of the intercontinental transport system. By contrast, Canon's photocopier achieved a lower unit price, vis-à-vis the incumbent Xerox copier, through its simpler design that enabled the outsourcing of a set of activities (e.g. distribution and service) to other actors. In this manner, the overall value acquired by the end-user remained intact, but the price of the Canon copier itself was competitively lower. The reconfiguration of the value blueprint subsequently emphasises separation, in other words, outsourcing of tasks to different actors. Our cross-case comparison suggests there to be two modes of value blueprint reconfiguration for cases of low-end disruptive change that focus on cost reduction, which align with our Propositions 1 and 2.

The microwave oven, by contrast, is an illustration of a new market disruptive innovation, not having entered direct competition with incumbent technologies (i.e. traditional ovens), but rather against non-consumption, creating a new market for faster cooking. And, at closer inspection, we may classify the Canon photocopier as a hybrid disruptive innovation, which simultaneously carries low-end disruption traits (i.e. a simpler and cheaper alternative to the incumbent Xerox machines), as well as new market disruption traits. In this manner, the Canon photocopier's ability to be easily positioned in offices meant that it established a new market (i.e. for office occupants who could not readily access Xerox copiers), gradually pulling the low-end of the existing market into this new context.

When we evaluate the value blueprint reconfigurations of the microwave oven and Canon photocopier cases, we observe some notable differences. For the former, we see that the unit cost of the innovation is high and the product is unlikely to attract customers on the price attribute alone. Rather, we claim that the consumer's 'net utility threshold', in other words, "the highest price a consumer will pay for a product that just meets her functional threshold" (Adner, 2002), is surpassed due to the systemic value that they are able to garner with the availability of complementary products (e.g. ready deep-frozen meals) and the combined effect that the microwave oven and complementarities have on the ease of storing food and the speed and ease of the cooking process. This complementarity is bestowed by the addition of new actors to the ecosystem's value blueprint, which specialise in providing complementary products. Thus, the higher cost of the disruptive innovation is coupled with (and compensated by) the availability of holistic, additional value the customer is able to acquire. This observation aligns with Proposition 3. By contrast, we observe a different mechanism for the case of Canon's photocopier. Unlike the microwave oven, Canon's product is offered at a lower price with respect to the incumbent, Xerox, and is likely to be less demanding on the consumers' willingness to pay. Hence, we believe that the availability of complementary products and services, additional to those outsourced, is not a vital requirement in this and similar hybrid cases where the new market disruption is brought about by an innovation with lower cost.

The cases we have considered here for illustrative purposes are well known, historical ones. However, we can also extrapolate the above discussion to more contemporary disruptive changes, especially those that have been enabled through digital technologies such as the internet. Take for example the disruption of the traditional hotel and accommodation industry by Airbnb's online service innovation. Airbnb's business model works simply on the possibility of common individuals' capacity to offer a similar value proposition (i.e. overnight accommodation) as traditional hotels, with added benefits such as flexibility of location and variety of accommodation options, but most importantly, a price reduction. Airbnb's online platform allows individuals to assume the role of both accommodation provider (i.e. host) and accommodation seeker (i.e. guest). Hence, Airbnb has adopted a clear example of a two-sided market or an ecosystem platform, where users play the consumer as well as the supplier role (Gawer, 2014; Gawer and Cusumano, 2014). The infamous case of Uber follows a very similar logic, as it provides a (potentially) disruptive business model premised on common individuals' capacity to offer rides to other individuals, a value proposition that is more or less the same as that of traditional taxi companies. However, its disruptive potential, in this instance against limousine services (Christensen et al., 2015), rests on the benefit of convenience, but again most importantly on its price advantage in comparison to the incumbent value proposition.

When we compare the contemporary case of Airbnb, and the historical case of the Canon photocopier, we can see differences in the manner of disruption. Following Gawer's (2014) arguments, we perceive Xerox, which had centred its business on an internal platform (i.e. simply as "a firm and its sub-units"), to have been disrupted by $\mathrm{Ca}$ non, which had developed a supply-chain platform (i.e. an architecture that underlines "an assembler and its suppliers"). By comparison, Airbnb has implemented a different strategy to that of Canon's, in the form of an ecosystem platform (i.e. "a platform leader and its complementors") to disrupt the supply-chain platform of the incumbent hotel business. Notwithstanding these apparent differences, we observe that the direction of change appears to be the same. In other words, in each of the cases considered, the incumbent innovation ecosystem is 
disrupted by another that boasts a platform broader in its scope, coupled with increased openness of interfaces, which allow more actors to join the milieu to enhance innovation and diversity of capabilities (Gawer, 2014). This repeating pattern in both historical and contemporary cases affords greater confidence in our propositions related to the low-end disruption of innovation ecosystems.

\section{Future research}

We believe that in-depth qualitative studies can examine several types of propositions related to the reconfiguration of ecosystems in addition to the ones that we have started with. To uncover these propositions, we consider a generic process model that comprises the incumbent value blueprint, the type of disruption, and the new value blueprint that results from this disruption, all of which operate in an embedding context (see Figure 2).

Figure 2. Generic process model of value blueprint reconfiguration.

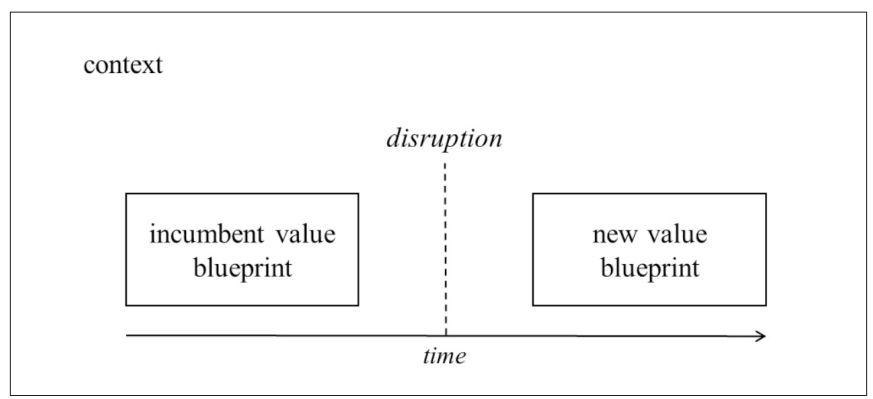

We can derive new propositions for further research by specifying the characteristics or variations of each component in the above figure. For instance, the incumbent value blueprint characteristic that we have emphasised in formulating Propositions 1 and 2 has been the degree of modularity of the incumbent product. This is a logical choice in hindsight as modularity influences the ecosystem's flexibility and adaptability, thus reducing its vulnerability to disruption. However, there are additional characteristics of the incumbent value blueprint that can help us establish propositions related to the manner of reconfiguration, including the structure and the composition of the constellation of actors that make up the entire ecosystem (Adner, 2017). If the value blueprint structure is very rigid with actors that fulfil highly specialised tasks, then disruption might lead to substitution of the entire constellation. By contrast, a more flexible structure where actors can fulfil multiple tasks and be connected via multiple links to other actors, can possibly foster reconfiguration without generating a high rate of obsolescence.

When we consider the types of disruption we specified in our work, we have seen that the new ecosystem can completely substitute for the incumbent, as was the case for the Bakelite vis-à-vis the Shellac ecosystem. In other cases, however (e.g. Canon versus Xerox, and Microwave oven versus the traditional stove), it appears that the new and the incumbent ecosystem can co-exist for prolonged periods of time without substituting each other completely. We think that these outcomes could be taken into account in formulating further propositions, such as those focused on the conditions that favour complete substitution versus co-existence of ecosystems. Another type of disruption that we have not examined in our work, but which has been studied in the wider literature, is the process of 'high-end' disruption (e.g. Govindarajan and Kopalle, 2006; Yu and Hang, 2010). This process describes products that originally enter the high-end niches of a market (i.e. generally with a high price tag and high quality levels), but which later move downwards to disrupt the mainstream market, sketching an opposite direction of movement to the traditional lowend process. We believe that additional propositions could be developed to capture how high-end disruptions differ from low-end disruptions in reconfiguring the innovation ecosystem value blueprint.

Finally, the embedding context can play a vital role in how the incumbent value blueprint is reconfigured subject to disruption. Each of our illustrative cases has drawn attention to this point. For instance, the increase in demand for Shellac originated outside the Shellac market, namely, from the increase of electrical infrastructures and equipment in society, which required more insulating material for electrical wires. In the development of the microwave oven, we observed the impact of the end of World War II, a contextual factor that compelled the exploration of civilian, rather than military, applications for the microwave tube. In the case of the photocopier, Canon's disruptive innovation was essentially triggered in the 1960s when the Federal Trade Commission forced Xerox to license its patents to competitors.

Taking these notions into consideration collectively, we may transform the generic process model of value blueprint disruption (Figure 2) into a simplified static model specifying the causes of value blueprint reconfiguration, as shown in Figure 3.

Figure 3. Stylised model explaining the causes of value blueprint reconfiguration.

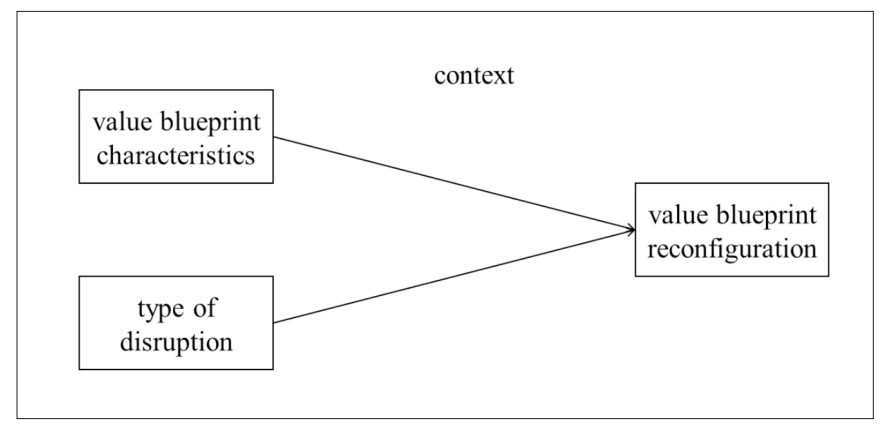

The causal model presented in Figure 3 can guide future research initiatives addressing the important issue of ecosystem disruption. Research examining how value blueprint characteristics, and/or the type of disruption leads to reconfiguration can provide valuable insights for incumbent firms making various strategic decisions. Overall, we believe that the ecosystem perspective provides an important avenue for continued research from the practitioner's point of view, in particular. This is because the prevailing theoretical frameworks dealing with the influence of radical, abrupt changes in the technological landscape has hitherto focused on a narrow scope, namely, the ensuing direct rivalry among firms. Yet, firms are embedded in networked environments, collaborating with a host of other actors to 
create value to customers in the form of systemic products and services. We therefore believe that the continuation of this line of research will shed light on the competitive position of suppliers, intermediaries, and complementors, as well as customers, when an innovation disrupts an existing ecosystem.

\section{References}

Adner, R. (2002), "When are Technologies Disruptive? A DemandBased View of the Emergence of Competition", Strategic Management Journal, Vol. 23 No. 8, pp. 667-688.

Adner, R. (2012), The Wide Lens: A New Strategy for Innovation, Portfolio/Penguin: USA.

Adner, R., and R. Kapoor. (2010), "Value creation in innovation ecosystems: How the structure of technological interdependence affects firm performance in new technology generation", Strategic Management Journal, Vol. 31, pp. 306-333.

Adner, R., and R. Kapoor. (2016a), "Innovation ecosystems and the pace of substitution: Re-examining technology S-curves", Strategic Management Journal, Vol. 34, No. 4 pp. 625-648.

Adner, R., and R. Kapoor. (2016b), "Right tech, wrong time”, Harvard Business Review, No. November, pp. 6067.

Adner, R. (2017), “Ecosystem as structure: An actionable construct for strategy”, Journal of Management, Vol. 43 No. 1, pp. 39-58.

Agerfalk, P.J. and Fitzgerald, B. (2008), "Outsourcing to an unknown workforce: Exploring opensourcing as a global sourcing strategy", MIS Quarterly, Vol. 32 No. 2, pp. 385-409.

Baldwin, C.Y. and Clark, K.B. (2003), "Managing in an age of modularity”. In: Garud, R., Kumaraswamy, A., Langlois, R.N. (Eds.), Managing in the modular age: Architectures, networks, and organizations, pp. 149-171.

Basole, R.C. (2009), "Visualization of interfirm relations in a converging mobile ecosystem”, Journal of Information Technology, Vol. 24, pp. 144-159.

Bower, J.L. and Christensen, C.M. (1995), "Disruptive technologies: Catching the wave”, Harvard Business Review, Vol. January-February, pp. 43-53.

Brown, R. (2016), “Mission impossible? Entrepreneurial universities and peripheral regional innovation systems", Industry and Innovation, Vol. 23 No. 2, pp. 189-205.

Bourreau, M., Gensollen, M. and Moreau, F. (2012), "The impact of a radical innovation on business models: Incremental adjustments or Big Bang?", Industry and Innovation, Vol. 19 No. 5, pp. 415-435.

Carlsson, B. (2016), "Industrial dynamics: A review of the literature 1990-2009”, Industry and Innovation, Vol. 23 No. 1, pp. 1-61.
Chesbrough, H. (2003). Open Innovation. The New Imperative for Creating and Profiting from Technology, Harvard Business School Press: USA.

Chesbrough, H. and Rosenbloom, R.S. (2002), "The role of the business model in capturing value from innovation: Evidence from Xerox Corporation's technology spin-off companies", Industrial and Corporate Change, Vol. 11 No. 3, pp. 529-555.

Christensen, C.M. (1997), The Innovator's Dilemma: When New Technologies Cause Great Firms to Fail, Harvard Business School Press: Boston, Massachusetts.

Christensen, C.M., Raynor, M., and McDonald, R. (2015), "What is disruptive innovation?", Harvard Business Review, Vol. 93 No. 12, pp. 44-53.

Currah, A. (2007), "Hollywood, the internet and the world: A geography of disruptive innovation", Industry and Innovation, Vol. 14 No. 4, pp. 359-384.

Cusumano, M.A. and Gawer. A. (2002), "The elements of platform leadership” MIT Sloan Management Review, Vol. Spring, pp. 51-58.

Da Silva, C.M., Trkman, P., Desouza, K., and Lindič, J. (2013), “Disruptive technologies: A business model perspective on cloud computing”, Technology Analysis \& Strategic Management, Vol. 25 No. 10, pp. 1161-1173.

Dedehayir O. and Mäkinen, S.J. (2010), “Determining reverse salient types and evolutionary dynamics of technology systems with performance disparities", Technology Analysis \& Strategic Management, Vol. 23 No. 10, pp. 1095-1114.

Garnsey, E. and Leong, Y.Y. (2008), "Combining resource-based and evolutionary theory to explain the genesis of bio-networks", Industry and Innovation, Vol. 15 No. 6, pp. 669-686.

Gawer, A. (2014), "Bridging differing perspectives on technological platforms: Toward an integrative framework", Research Policy, Vol. 43, pp. 1239-1249.

Gawer, A. and Cusumano, M. (2014), "Industry platforms and ecosystem innovation”, Journal of Product Innovation Management, Vol. 31 No. 3, pp. 417-433.

Ghandour, F.A., Swartz, P., Grenek, H.M., and Roberts, E.B. (2004), "E-Business transformation via alliance clusters", Technology Analysis \& Strategic Management, Vol. 16 No. 4, pp. 435-455.

Govindarajan, V. and Kopalle, P.K. (2006), “The usefulness of measuring disruptiveness of innovations ex post in making ex ante predictions", Journal of Product Innovation Management, Vol. 23, pp. 12-18.

Hammack, W. (2005), “The greatest discovery since fire”, Invention \& Technology Magazine, Vol. 20 No. 4. 
Henderson, R.M. and Clark, K.B. (1990), "Architectural innovation: The reconfiguration of existing product technologies and the failure of established firms", Administrative Science Quarterly, Vol. 35 No 1, pp. 9-30.

Hicks, E. (1961), Shellac, its Origin and Applications, Chemical Publishing Co., Inc.: New York.

Huurdeman, A.A. (2003), The Worldwide History of Telecommunications, Wiley-Interscience: Hoboken, New Jersey.

Iansiti, M. and Levien, R. (2004), "Strategy as ecology”, Harvard Business Review, Vol. March, pp. 1-10.

Isckia, T. (2009), “Amazon's evolving ecosystem: A cyber-bookstore and application service provider", Canadian Journal of Administrative Sciences, Vol. 26, pp. 332-343.

Iyer, B. and Davenport, T.H. (2008), "Reverse engineering Google's innovation machine", Harvard Business Review, Vol. April, pp. 1-11.

Kauffman, G.B. (1993), "A brief history of Cuprammonium”, in Seymour, R.S. and R.S. Porter (Eds.), Manmade Fibers: Their Origin and Development, Elsevier Publishing: Barking.

Kuntz, V.D. and Warren, L. (2011), "From innovation to market entry: A strategic management model for new technologies", Technology Analysis \& Strategic Management, Vol. 23 No. 4, pp. 345-366.

Li, Y. (2009), “The technological roadmap of Cisco's business ecosystem”, Technovation, Vol. 29, pp. 379-386.

Mäkinen, S.J. and Dedehayir, O. (2013), "Business ecosystems evolution - An ecosystem clockspeed perspective”. In: Oxley, J.E., Silverman, B., Adner, R. (Eds.), Collaboration and Competition in Business Ecosystems. Advances in Strategic Management, Vol. 30, pp. 99-125.

Moore, J.F. (1993), "Predators and prey: A new ecology of competition”, Harvard Business Review, Vol. May-June, pp. 75-86.

Nehf, J.P. (2007), "Shopping for privacy on the internet", The Journal of Consumer Affairs, Vol. 41 No. 2, pp. 351-375.

Osepchuk, J.M. (1984), "A history of microwave heating applications", IEEE Transactions on Microwave Theory and Techniques MTT, Vol. 32 No. 9 (September), pp. 1200-1224.

Parry, E.J. (1935), Shellac, its Production, Manufacture, Chemistry, Analysis, Commerce and Uses, Pitman \& Sons, Ltd.: London.

Pierce, L. (2009), "Big losses in ecosystem niches: How core firm decisions drive complementary product shakeouts", Strategic Management Journal, Vol. 30, pp. 323-347.

Porter, M.E. (1985), Competitive Advantage: Creating and Sustaining Superior Performance, Free Press: New York.
Righter, R.W. (1996), Wind Energy in America, a History, University of Oklahoma Press: Norman and London.

Sandberg, B. and Hansén, S-O. (2004), "Creating an international market for disruptive innovations", European Journal of Innovation Management, Vol. 7 No. 1, pp. 23-32.

Sawhney, M.S. (1998), "Leveraged high-variety strategies: From portfolio thinking to platform thinking", Journal of the Academy of Marketing Science, Vol. 26 No. 1, pp. 54-61.

Schilling, M.A. (2000), “Toward a general modular systems theory and its application to interfirm product modularity", Academy of Management Review, Vol. 25 No. 2, pp. 312-334.

Schumpeter, J.A. (1942), Capitalism, Socialism and Democracy, Harper \& Low, Publishers, Inc.: New York.

Simchi-Levi, D. (2005), Designing and Managing the Supply Chain, McGraw-Hill College: New York.

Teece, D.J. (1986), "Profiting from technological innovation: Implications for integration, collaboration, licensing and public policy", Research Policy, Vol. 15 No. 6, pp. 285-305.

Teece, D.J. (2007), "Explicating dynamic capabilities: The nature and microfoundations of (sustainable) enterprise performance", Strategic Management Journal, Vol. 28, pp. 1319-1350.

Tiwana, A., Konsynski, B., and Bush, A.A. (2010), "Platform evolution: Coevolution of platform architecture, governance, and environmental dynamics", Information Systems Research, Vol. 21 No. 4, pp. 675-687.

Townsend, B.A. (1993), "Full circle in cellulose”, in Seymour, R.S. and R.S. Porter (Eds.), Manmade Fibers: Their Origin and Development, Elsevier Publishing: Barking, pp. 18-54.

Tushman, M.L. and Anderson, P. (1986), "Technological discontinuities and organisational environments", Administrative Science Quarterly, Vol. 31 No. 3, pp. 439-465.

Weiss, C. and Bonvillian, W.B. (2013), "Legacy sectors: Barriers to global innovation in agriculture and energy", Technology Analysis \& Strategic Management, Vol. 25 No. 10, pp. 1189-1208.

Whitley, E.A. and Darking, M. (2006), “Object lessons and invisible technologies”, Journal of Information Technology, Vol. 21, pp. 176-184.

Yu, D. and Hang, C.C. (2010), "A reflective review of disruptive innovation theory", International Journal of Management Reviews, Vol. 12, pp. 435-452. 
